\title{
Evaluation of a Conceptual Model for Gas-Particle Partitioning of Polycyclic Aromatic Hydrocarbons Using Polyparameter Linear Free Energy Relationships
}

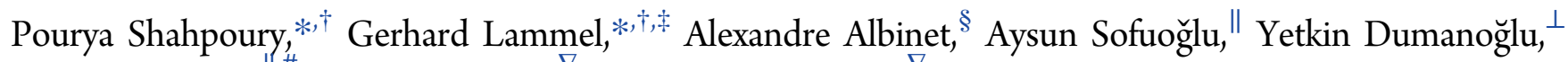
Sait C. Sofuoğlu, ${ }^{l /, \#}{ }^{2}$ deněk Wagner, ${ }^{\nabla}$ and Vladimir Zdimal ${ }^{\nabla}$

${ }^{\dagger}$ Multiphase Chemistry Department, Max Planck Institute for Chemistry, Hahn-Meitner-Weg-1, 55128 Mainz, Germany

${ }^{\ddagger}$ Research Centre for Toxic Compounds in the Environment, Masaryk University, 62500 Brno, Czech Republic

${ }^{\S}$ INERIS (Institut National de l'Environnement Industriel et des Risques), 60550 Verneuil-en-Halatte, France

"Chemical Engineering Department and "Environmental Engineering Department, Izmir Institute of Technology, Urla 35430, Turkey

${ }^{\perp}$ Environmental Engineering Department, Dokuz Eylül University, Izmir 35210, Turkey

${ }^{\nabla}$ Institute for Chemical Process Fundamentals of the CAS, v. v. i., 16502 Prague, Czech Republic

Supporting Information

ABSTRACT: A model for gas-particle partitioning of polycyclic aromatic hydrocarbons (PAHs) was evaluated using polyparameter linear free energy relationships (ppLFERs) following a multiphase aerosol scenario. The model differentiates between various organic (i.e., liquid water-soluble (WS)/organic soluble (OS) organic matter (OM), and solid/semisolid organic polymers) and inorganic phases of the particulate matter (PM). Dimethyl sulfoxide and polyurethane were assigned as surrogates to simulate absorption into the abovementioned organic phases, respectively, whereas soot, ammonium sulfate, and ammonium chloride simulated adsorption processes onto PM. The model was tested for gas and PM samples collected from urban and nonurban sites in Europe and the Mediterranean, and the output was compared with those calculated using single-parameter linear free energy relationship (spLFER) models, namely JungePankow, Finizio, and Dachs-Eisenreich. The ppLFER model on average predicted

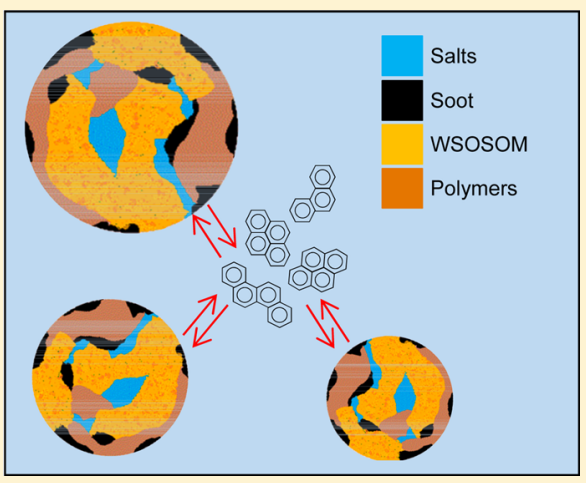
$96 \pm 3 \%$ of the observed partitioning constants for semivolatile PAHs, fluoranthene, and pyrene, within 1 order of magnitude accuracy with root-mean-square errors (RMSE) of $0.35-0.59$ across the sites. This was a substantial improvement compared to Finizio and Dachs-Eisenreich models (37 \pm 17 and $46 \pm 18 \%$ and RMSE of 1.03-1.40 and 0.94-1.36, respectively). The JungePankow model performed better among spLFERs but at the same time showed an overall tendency for overestimating the partitioning constants. The ppLFER model demonstrated the best overall performance without indicating a substantial intersite variability. The ppLFER analysis with the parametrization applied in this study suggests that the absorption into WSOSOM could dominate the overall partitioning process, while adsorption onto salts could be neglected.

\section{INTRODUCTION}

Semivolatile organic compounds (SOCs) are substances with saturation vapor pressure in ambient air between $10^{-6}$ and $10^{-2}$ $\mathrm{Pa}^{1}$ When in the atmosphere, SOCs can undergo partitioning between gas and particulate phases. This is an important process because it determines the atmospheric fate of SOCs. ${ }^{1-4}$ Reactivity, deposition, and, consequently, atmospheric transport of SOCs depend highly on their phase partitioning. This process influences the chemical composition of the atmosphere and has health- and climate-related implications. ${ }^{3,5}$ Among SOCs, polycyclic aromatic hydrocarbons (PAHs) form one of the most harmful groups of organic chemicals to human health due to their carcinogenicity and enduring emission in the environment. ${ }^{5-7}$ Following emission, PAHs can reach remote and pristine regions through atmospheric transport. Subsequently, they could undergo wet scavenging by rain or snowfall and dry gas and particle deposition, which leads to their accumulation in surface water, topsoil, vegetation, or snowpack. The latter may result in further contamination of terrestrial and aquatic ecosystems through snowmelt in short concentration pulses, ${ }^{8}$ a preferential elution process that is partly influenced by $\mathrm{PAH}$ partitioning in particulate matter (PM) prior to snow scavenging and accumulation in snowpack. The magnitude of $\mathrm{PAH}$ wet scavenging is, to a certain extent, controlled by gas-particle partitioning in the air, which in turn is regulated by the substance and PM physicochemical properties, ambient temperature, and relative humidity. ${ }^{9-11} \mathrm{PAH}$ gas-

Received: April 30, 2016

Revised: October 6, 2016

Accepted: October 13, 2016

Published: October 13, 2016 
particle partitioning can be explained by various empirical and theoretical models, based on single- or polyparameter linear free energy relationships (sp-, ppLFER). The spLFER models are often used in regional and global atmospheric chemistry models. A spLFER model relates the solute partitioning constant to one of its physicochemical properties, such as subcooled liquid vapor pressure $\left(p_{\mathrm{L}}{ }^{0}\right)$ or octanol-air partitioning coefficient, whereas ppLFER relates the partitioning constant to more than one property, thus accounting for, ideally, all significant molecular interactions between the solute and sorbent (see Section 2.3). ${ }^{12}$ Despite being considered general, ppLFER may suffer from the lack of empirically determined parameters for certain solutes and sorbents. spLFER models have been frequently used to predict PAH gas-particle partitioning, while only a few studies applied ppLFER for this purpose, ${ }^{13,14}$ although ppLFER was tested on other substance classes. ${ }^{15}$ Both sp- and ppLFER models applied in these studies often underpredicted the observed PAH partitioning constants to various extents, although, in some cases, improvement in model predictions was observed when the contribution of $\mathrm{PAH}$ adsorption onto soot particles was taken into account. ${ }^{9,13,16-21}$

In recent years, much progress has been made toward identifying the chemical characteristics and molecular structures of particulate organic matter (OM). This information could be used effectively to better understand and model the partitioning of SOCs between gas and particulate phase (this will be discussed in more detail in Sections 3.1 and 3.2). The previous studies assumed OM to be a homogeneous mixed phase, while the presence of two distinct OM phases can be expected under atmospheric conditions ${ }^{22}$ - i.e. a mixed liquid phase containing both water-soluble (WS) and organic soluble (OS) OM and solid/semisolid organic polymers. In the present study, we aimed to revisit the PAH gas-particle partitioning models in light of recent developments in deciphering the chemical composition of OM, by conceptually differentiating the OM subfractions and highlighting the importance of WSOSOM. The specific objectives of the present study were (1) to apply appropriate ppLFER models, which were developed for various organic and inorganic matrices, to predict the extent of $\mathrm{PAH}$ gas-particle partitioning and compare the predictions with experimental partitioning data from urban and nonurban sites in Europe and the Mediterranean, (2) estimate the contribution of individual organic and inorganic PM phases to the overall sorption of the target substances, and (3) compare the ppLFER predictions with those from spLFER models, namely JungePankow, Finizio, and Dachs-Eisenreich (a dual-phase spLFER).

\section{EXPERIMENTAL SECTION}

2.1. Sites and Sampling. Air samples were collected from a continental background site in the Czech Republic, Košetice observatory $\left(49^{\circ} 34^{\prime} \mathrm{N}, 15^{\circ} 05^{\prime} \mathrm{E}\right.$, the site is part of the European Monitoring and Evaluation Program), an urban site in France, Grenoble $\left(45^{\circ} 09^{\prime} \mathrm{N}, 5^{\circ} 44^{\prime} \mathrm{E}\right.$, Les Frênes, air quality networkstation of Air Rhône-Alpes, it represents the air pollution for this urban area), and a rural/coastal site in Turkey,

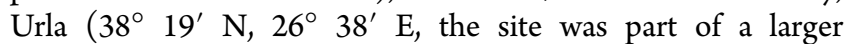
campaign designed to study SOC multicompartmental processes around the Aegean Sea). ${ }^{23}$ More than 300 particulate $\left(\mathrm{PM}_{10}\right)$ and gas-phase samples were collected on quartz fiber filters and polyurethane foam plugs, respectively, using highvolume air samplers between 2012 and 2013. The PM samples were analyzed for their organic and elemental carbon contents.
Meteorological data were available at all sites. In addition, PM number size distribution (SMPS, 0.01-0.80 $\mu \mathrm{m}$ ) was determined at Košetice. The description of sampling protocols and methods for PM carbon content analysis can be found in Section S1 in the Supporting Information (SI).

2.2. Chemical Analysis and Quality Control. All gasphase and PM samples were analyzed using solvent extraction techniques followed by chromatographic methods (see Section S1 in the SI for detailed analytical procedures). All samples were spiked with recovery standards prior to extraction, and the $\mathrm{PAH}$ recoveries ranged from 72 to 102,80 to 120 , and 85 to $102 \%$, for Košetice, Grenoble, and Urla samples, respectively (see Section S1 in the SI for detail). Samples were analyzed for target PAHs including phenanthrene (PHE), fluoranthene (FLT), pyrene (PYR), benzo(a)anthracene (BAA), chrysene $(\mathrm{CHR})$, and benzo(b)fluoranthene (BBF). The results for PHE from Urla were not considered because of analytical method uncertainties. The analyte-specific breakthrough volumes were estimated using the method suggested by Kamprad and Goss. ${ }^{24}$ A detailed description of quality control for gas-particle partitioning data including the estimation of breakthrough volumes can be found in Section S1 in the SI.

2.3. Gas-Particle Partitioning Models. The gas-particle partitioning of SOCs in air can be explained by eq $1^{25}$

$$
K_{\mathrm{p}}=\frac{c_{\mathrm{ip}} / c_{\mathrm{PM}}}{c_{\mathrm{ig}}}
$$

where $K_{\mathrm{P}}\left(\mathrm{m}_{\text {air }}^{3} \mathrm{~g}^{-1}{ }_{\mathrm{PM}}\right)$ is temperature-dependent partitioning coefficient, $c_{\mathrm{PM}}\left(\mathrm{g} \mathrm{m}^{-3}\right)$ is the concentration of particulate matter in air, $c_{\mathrm{ip}}$ is the analyte $(i)$ concentration $\left(\mathrm{ng} \mathrm{m}^{-3}\right)$ in particulate phase, and $c_{\mathrm{ig}}$ is that in gas phase. The dimensionless fraction of a substance on particles, $\theta$, can be calculated using eq 2

$$
\theta=\frac{c_{\mathrm{ip}}}{c_{\mathrm{ig}}+c_{\mathrm{ip}}}
$$

2.3.1. spLFER Models. Detailed descriptions of spLFER models, namely Junge-Pankow (adsorption), ${ }^{26,27}$ Finizio (absorption), ${ }^{28}$ and Dachs-Eisenreich (adsorption and absorption), ${ }^{17}$ and the related equations can be found in Sections S2 and $\mathrm{S} 3$ in the SI.

2.3.2. ppLFER Models. This approach is based on the linear solvation energy relationship developed by Abraham $^{29}$ for condensed phase-condensed phase (eq 3) and condensed phase-air systems (eq 4). These relationships were later combined by Goss ${ }^{30}$ to form a single ppLFER eq (eq 5) which, in many cases, can be applied to both systems

$$
\begin{aligned}
& \log K_{\mathrm{P}}=e E+s S+a A+b B+v V+c \\
& \log K_{\mathrm{P}}=e E+s S+a A+b B+l L+c \\
& \log K_{\mathrm{P}}=s S+a A+b B+v V+l L+c
\end{aligned}
$$

where capital letters $E, S, A, B, V$, and $L$ are solute-specific Abraham solvation parameters for excess molar refraction (describes interactions between $\pi$ - and n-electron pairs), dipolarity/polarizability (denotes polar interactions other than $\mathrm{H}$-bonding), solute $\mathrm{H}$-bond acidity, solute $\mathrm{H}$-bond basicity, McGowan molar volume $\left(\mathrm{cm}^{3} \mathrm{~mol}^{-1}\right) / 100$, and logarithm of solute hexadecane-air partitioning coefficient (unitless), respectively. ${ }^{31}$ The corresponding small letters are known as system parameters and reflect the matrix-specific solute- 
independent energetic contribution to the $K_{\mathrm{p}}$. For solute partitioning between a condensed phase and air, so-called system parameters would reflect the energetic contribution of the sorbent to the overall partitioning, as no considerable molecular interactions are expected in the gas phase (ideal condition). ${ }^{31}$ ppLFER equations were developed by Arp et al. ${ }^{13}$ for aerosols from urban and nonurban areas in Europe. That study categorized the samples based on their major components (e.g., mineral-rich, carbonaceous), which were identified through scanning electron microscopy. The authors suggested that ppLFER models based on PM samples from Berlin winter and Dübendorf autumn, which were collected near pollution source areas, are good models which represent the generic sorption properties of continental PM.

\section{PPLFER APPROACH AND MODEL SETUP}

For the ppLFER model, we considered two mechanisms for $\mathrm{PAH}$ gas-particle partitioning: absorption into $\mathrm{OM}$ and adsorption onto soot and soluble salts (Section S4 in the SI). We neglected the adsorption onto mineral dust; Arp et al. ${ }^{13}$ noted that out of several samples with different sources, a mineral-rich sample with Sahara origin demonstrated the lowest partitioning constants for nonpolar organic compounds.

3.1. Allocation of Organic Fractions. For the absorption contribution, we assumed that OM consisted of two phases: (A) low to high molecular mass WSOSOM - e.g. humic-like substances (HULIS), ${ }^{32}$ diterpenoid acids, aromatic polycarboxylic acids, aliphatic dicarboxylic acids, $n$-alkenoic acids, $n$-alkanoic acids, ${ }^{33}$ and (B) high molecular mass organic polymers (OP). ${ }^{2,34-36}$ Also, low to high molecular mass substances which tend to be water insoluble (WI), such as aliphatic and polycyclic aromatic hydrocarbons, do contribute to OM. However, an estimate from a previously published study showed that this fraction could form $\leq 5 \%$ of $\mathrm{OM}$ in urban aerosols. ${ }^{33}$ Moreover, this fraction is likely mixed in liquid or semisolid bulk OM, as there is no empirical evidence of phase separation between WS- and WIOM (this concept has been suggested based on theoretical considerations only). ${ }^{37}$

In the absence of experimental data that could compliment the OM mass mixing ratios related to phase ' $A$ ' and ' $\mathrm{B}$ ' for the current sampling sites, the mixing ratios were estimated using the data reported by Rogge et al. ${ }^{33}$ for Rubidoux, $\sim 75 \mathrm{~km}$ downwind of Los Angeles. The exception was the samples from Grenoble, for which measured values of WSOM and HULIS were available. In the present study, $60 \%$ of OM was allocated to phase 'A' (corresponding to organic fraction eluted/extracted from Rubidoux samples using a combination of nonpolar and polar organic solvents) and $40 \%$ to phase 'B' (corresponding to nonextractable/elutable organic fraction). These estimated fractions were further corrected for OM mass mixing ratio in PM $\left(f_{\mathrm{OM}}\right)$ for individual samples in the present study; $f_{\mathrm{OM}}$ was determined from organic carbon concentration using conversion factors of 1.6 and 2.1 for urban and nonurban sites, respectively. $^{38}$

3.2. Choice of Surrogates for Organic Fractions. The WSOM can constitute $10-80 \%$ of the PM organic content, of which a substantial fraction is made of oxygenated compounds including aromatic acids, phenols, dicarboxylic acids, ketocarboxylic acids, aliphatic aldehydes, and alcohols. ${ }^{39}$ The evidence of $\pi-\pi$ electron donor-acceptor interaction was previously presented for soil humic matter containing quinones and aromatic species with electron withdrawing functional groups, such as ketone, aldehyde, and carboxyl. ${ }^{40}$ Similar molecular interactions, in addition to H-bonding, are expected for aerosol $\mathrm{OM}$, at least with regard to HULIS which can constitute up to $70 \%$ of the WSOM in fine PM. ${ }^{32}$

We considered three criteria for selecting a surrogate to represent WSOM: (1) having water solubility and molecular mass close to those found for major WSOM constituents, (2) the substance dipolarity (denoted by Abraham $S$ descriptor), and (3) availability of methods for determining solute-specific enthalpies of phase-transfer.

$n$-Octanol has been conventionally used as a surrogate for organic matter in various environmental matrices, including PM. This compound is amphiphilic and would simulate various nonspecific and specific molecular interactions, with the exception of $\pi-\pi$ interaction, which is relevant for partitioning processes involving PAHs. ${ }^{40,41}$ However, $n$-octanol shows relatively low water solubility (i.e., $5.4 \times 10^{2} \mathrm{mg} \mathrm{L}^{-1}$ at 298 $\mathrm{K})$ and dipolarity/polarizability $(S: 0.42)$ compared to certain constituents of WSOM, such as predominant carboxylic acids and sugars found in PM samples ${ }^{42}-$ e.g. levoglucosan $(7.8 \times$ $10^{5} \mathrm{mg} \mathrm{L}^{-1}$; $:$ : 1.34), glycolic acid $\left(1 \times 10^{6} \mathrm{mg} \mathrm{L}^{-1}\right.$; S: 0.67$)$, glutaric acid $\left(1.6 \times 10^{6} \mathrm{mg} \mathrm{L}^{-1} ; S: 1.07\right)$, mannosan $\left(7.8 \times 10^{5}\right.$ $\left.\mathrm{mg} \mathrm{L}{ }^{-1} ; S: 1.34\right)$, glucose $\left(6.8 \times 10^{5} \mathrm{mg} \mathrm{L}^{-1} ; S: 1.81\right){ }^{43,44}$ Although interpretation of the fitting coefficient " $s$ " (i.e., the system parameter related to dipolarity/polarizability; see Section 2.3.2) may not be straightforward, comparing the corresponding values between different condensed phase-air systems can provide some insight into the chemistry of the partitioning systems and their dominant molecular interactions. ppLFER equations which were developed based on urban and rural aerosols, ${ }^{13}$ despite having low performance for predicting PAH gas-particle partitioning, indicate " $s$ " values that are much larger (i.e., $1.21 \pm 0.22$ mean \pm standard deviation at $288 \mathrm{~K}$ ) than that for the $n$-octanol-air system (i.e., 0.56 at $298 \mathrm{~K}$; Table S3). For the reasons mentioned here, $n$-octanol and similar linear alcohols were considered unsuitable as surrogates for WSOSOM in the present study.

ppLFER models were also developed for soil humic matter; however, they cannot be considered good choices to represent WSOSOM either, mainly due to the fact that the molecular mass for soil humic matter is up to 2 orders of magnitude higher (soil humic acid mean mass: $7800 \mathrm{Da}^{45}$ ) than that suggested for WSOM constituents such as HULIS (200-500 $\mathrm{Da}^{46}$ see Section S5 in the SI). The choice of appropriate surrogate for WSOSOM is limited by the availability of ppLFER models in the literature for calculating the enthalpies of solvent-air phase transfer, which are critical for the temperature correction of the predicted partitioning constants. Based on the three criteria mentioned above, available ppLFER models in the literature were shortlisted to dimethyl sulfoxide (DMSO)-air, acetone-air, and N,N-dimethylformamide-air (Table S3). These compounds fall in the lower end of the molecular mass range for major WSOM constituents of PM proposed by Saxena and Hildemann. ${ }^{47}$ Calculations showed that $\log K_{\mathrm{P}}$ values $\left(\mathrm{m}_{\text {air }}^{3} \mathrm{~g}^{-1}\right.$ solvent $)$ for PYR and FLT determined using these ppLFER models (at $298 \mathrm{~K}$, normalized using the solvent densities) differ by $\leq 0.3$ and $\leq 0.1$ log unit, respectively. We allocated DMSO-air to phase 'A' because it has both the highest water solubility (i.e., $1 \times 10^{6}$ compared to $2.19 \times 10^{5}$ and $9.78 \times 10^{5} \mathrm{mg} \mathrm{L}^{-1}$, respectively; at $298 \mathrm{~K}$ ) and Abraham " $S$ " descriptor (1.72 compared to 0.70 and 1.31 , respectively) and is the least volatile $\left(p_{\mathrm{L}}{ }^{0}: 81.3\right.$ compared to $3.1 \times 10^{4}$ and $516 \mathrm{~Pa}$, respectively) among the three candidate surrogates, 
Table 1. Root Mean Square Errors and Percentage of Data Points Predicted within One Order of Magnitude Accuracy (in Parentheses) ${ }^{a}$

\begin{tabular}{|c|c|c|c|c|c|c|c|c|c|c|c|}
\hline & \multicolumn{4}{|c|}{ Košetice } & \multicolumn{4}{|c|}{ Grenoble } & \multicolumn{3}{|c|}{ Urla } \\
\hline & $\mathrm{JP}$ & $\mathrm{F}$ & $\mathrm{DE}$ & ppLFER & $\mathrm{F}$ & $\mathrm{DE}$ & ppLFER & ppLFER $^{b}$ & $\mathrm{~F}$ & $\mathrm{DE}$ & ppLFER \\
\hline PHE & $0.70(83)$ & $1.24(32)$ & $1.19(38)$ & $0.81(70)$ & $1.05(61)$ & $0.92(69)$ & $0.68(85)$ & $0.80(83)$ & NA (NA) & NA (NA) & NA (NA) \\
\hline FLT & $0.70(89)$ & $1.15(28)$ & $1.12(35)$ & $0.43(98)$ & $1.03(53)$ & $0.94(67)$ & $0.56(96)$ & $0.65(95)$ & $1.15(56)$ & $1.10(61)$ & $0.56(93)$ \\
\hline PYR & $0.77(84)$ & $1.40(17)$ & $1.36(22)$ & $0.35(98)$ & $1.14(47)$ & $1.02(57)$ & $0.59(91)$ & $0.64(95)$ & $1.31(22)$ & $1.24(33)$ & $0.44(100)$ \\
\hline BAA & $0.80(81)$ & $1.39(24)$ & $1.37(24)$ & $0.92(70)$ & $0.97(61)$ & $0.93(65)$ & $0.72(84)$ & $0.80(81)$ & $0.95(67)$ & $0.91(67)$ & $0.59(94)$ \\
\hline CHR & $1.17(48)$ & $0.62(96)$ & $0.61(96)$ & $0.29(100)$ & $0.71(84)$ & $0.68(84)$ & $0.72(83)$ & $0.85(80)$ & $0.62(94)$ & $0.59(94)$ & $0.37(100)$ \\
\hline $\mathrm{BBF}$ & $1.31(48)$ & $0.85(72)$ & $0.84(74)$ & $0.40(98)$ & $0.96(59)$ & $0.90(68)$ & $0.49(96)$ & $0.53(95)$ & $0.64(89)$ & $0.59(94)$ & $0.31(100)$ \\
\hline
\end{tabular}

${ }^{a} \mathrm{JP}$ : Junge-Pankow, F: Finizio, DE: Dachs-Eisenreich, ppLFER: polyparameter linear free energy relationship with default organic subfractions estimated from Rogge et al. ${ }^{33}$ Indicates model predictions based on measured fraction of water-soluble OM in PM $\left(f_{\text {WSOM }}\right)$.

which suggests that it is the most suitable surrogate for WSOSOM in the present study.

An ideal surrogate for polymeric OM would simulate nonspecific and specific molecular interactions. Cellulose originates from plant debris and is made of D-glucose units. ${ }^{35}$ As a result, in addition to van der Waals interactions, it should ideally form hydrogen bonds with solutes which undergo such a type of interaction, particularly via the surface chains. Secondary organic aerosol (SOA) polymers originated from oxidation of aromatic species could potentially undergo similar interactions, based on the molecular structures proposed by Kalberer et al. ${ }^{34}$ Holmgren et al. ${ }^{48}$ proposed several polymerair ppLFER models including those for cellulose-based materials and polyurethane. A urethane unit has a number of sites which could participate in H-bonding; therefore, one could expect polyurethane to simulate molecular interactions similar to those anticipated for cellulose and SOA polymers. Despite this possibility, the " $b$ " descriptors (indicating H-bond donor ability of the sorbent) for both cellulose and polyurethane models were found to be zero, while both showed high values for " $a$ " descriptor (denoting the sorbent's electron donor ability). ${ }^{48}$ This suggests that cellulose and polyurethane may interact with solutes in a similar way. ${ }^{48} \mathrm{We}$ assigned the ppLFER model for polyurethane-air ${ }^{24}$ to OM phase 'B' (Table S3). The advantage of using this model is that solute-specific enthalpies of phase transfer can be easily calculated using the available ppLFER equation, ${ }^{24}$ in order to account for the temperature dependence of the partitioning constants. For partitioning in organic polymers, we assumed that the diffusion in $\mathrm{OM}$ was absorptive even when becoming very slow as a consequence of OM phase-state (i.e., semisolid and solid OM).

3.3. Adsorption Contributions and Further Considerations. For adsorption contribution, the system parameters for diesel soot, ${ }^{49}$ ammonium sulfate, and ammonium chloride ${ }^{50}$ were used (Table S3). Relative humidity was shown not to have an impact on adsorption of organic vapors to diesel soot ${ }^{49}$ but demonstrated some effects on adsorption to ammonium sulfate and ammonium chloride; ${ }^{50}$ therefore, relative humidity at the sampling sites was taken into consideration when choosing the system parameters for salt surfaces (see Section S4 and Table S3). In principle, the ppLFER model for ammonium chloride can be replaced by the model for sodium chloride (Table S3) in cases where the mass mixing ratios of marine salts in PM are expected to be high.

All partitioning constants related to absorption and adsorption processes were corrected for the effect of nearground temperature at the sites using the solute-specific enthalpies of phase transfer, which were calculated for the corresponding ppLFER systems. ${ }^{24,51,52}$ Total $K_{\mathrm{P}}$ was deter- mined by summing the individual partitioning coefficients after normalizing the units related to all absorption and adsorption processes (Section S4). The soot specific surface area was set to $18.21 \mathrm{~m}^{2} \mathrm{~g}^{-1}$ - i.e. the geometric mean of surface areas for traffic, wood, coal, and diesel soot (i.e., 59.4, 3.6, 8.2, and 62.7 $\left.\mathrm{m}^{2} \mathrm{~g}^{-1}\right){ }^{53}$ The minimum and maximum of these surface areas were also applied in order to explore the sensitivity of the model predictions. We acknowledge that the phases considered in the present study may not be fully available for $\mathrm{PAH}$ partitioning due to internal mixing and kinetic limitations related to $\mathrm{OM}$ phase-state ${ }^{54}$ (slow diffusion in semisolid and solid phases) and that under high relative humidity $\left(\mathrm{NH}_{4}\right)_{2} \mathrm{SO}_{4}$ and $\mathrm{NH}_{4} \mathrm{Cl}$ may be present in dissolved aqueous phase and subject to liquid-liquid phase separation with OM. ${ }^{55}$ Moreover, as PM composition varies significantly with particle size, SOC sorption behavior is expected to be particle-size dependent. $^{14}$

\section{RESULTS AND DISCUSSION}

4.1. PAH Particulate Mass Fractions and Ambient Aerosol Composition. Gas-particle partitioning is a process that is more relevant for SOCs because relatively volatile or nonvolatile OCs, due to the extent of their molecular interactions with the sorbing phase, remain mainly in gas or particulate phase. We considered two criteria when selecting PAHs for model predictions: the substance ability to partition between both gas and particulate phases and the availability of experimental physicochemical property data required for all models. FLT, PYR, BAA, and CHR met the above criteria. Nevertheless, for better comparison, we included a relatively volatile and a nonvolatile PAH as well, namely PHE and BBF.

The PAH concentrations and distribution for Košetice and Grenoble samples have been previously published. ${ }^{10,56}$ Table S4 provides statistics on $\theta$ for selected PAHs, as well as ambient temperature, $\mathrm{PM}_{10}$ concentrations, and the mass mixing ratios of OM, $f_{\mathrm{OM}}$, elemental carbon, $f_{\mathrm{EC}}$, ammonium sulfate, $f_{\left(\mathrm{NH}_{4}\right)_{2} \mathrm{SO}_{4}}$, and ammonium chloride, $f_{\mathrm{NH}_{4} \mathrm{Cl}}$, in PM. Median $\theta$ values for semivolatile FLT, PYR, BAA, and CHR were higher for samples from Košetice than for those from Grenoble and Urla (Table S4). The relationship between $\theta$ and temperature for selected PAHs at the sites is shown in Figure S1. The temperature dependency of $\theta$ is more pronounced for FLT, PYR, BAA, and CHR, as evident from data points scattered across the temperature range, particularly for samples from Košetice; whereas for PHE and BBF the values of $\theta$ are close to zero and one, respectively. Median $\mathrm{PM}_{10}$ concentration was higher at Urla than at Košetice and Grenoble. In contrast, median $f_{\mathrm{OM}}$ values were comparable across all sites, although higher maximum values were found for Košetice and Grenoble. 
In addition, $f_{\mathrm{EC}}$ values were slightly higher at Grenoble, which is not surprising if we consider the influence of urban combustion at this site. Finally, median $f_{\left(\mathrm{NH}_{4}\right)_{2} \mathrm{SO}_{4}}$ was slightly higher at Košetice, but a higher maximum value was found at Grenoble. Given the above information, one could argue that lower temperature, rather than any other parameter, was responsible for the higher median $\theta$ found for semivolatile PAHs at Košetice.

4.2. ppLFER Model Evaluation and Discussion. ppLFER models suggested by Arp et al. ${ }^{13}$ (see Section 2.3.2 and Table S3) were tested on the Košetice data set (Figure S2). As it is evident, the model largely underpredicted the $K_{\mathrm{P}}$ values for all target PAHs, particularly when the Dübendorf autumn model was applied (more than one log unit; Figure S2). The root-mean-square errors (RMSE) of $\log K_{\mathrm{P}}$ for target PAHs ranged between 2.12-2.77 and 1.69-2.33 for Dübendorf autumn and Berlin winter models, respectively. This is not surprising as Arp et al. ${ }^{13}$ found similar performance with these models for PAHs.

Table 1 and Figure 1 show predictions made following the ppLFER method described in Sections 3 and S4. As can be seen, between 83 and $100 \%$ of the data points were predicted within 1 order of magnitude accuracy across all sites with RMSE of $\log K_{\mathrm{P}}$ ranging from 0.29 to 0.72 , with the exception of PHE and BAA from Košetice for which RMSE values were relatively larger (0.81 and 0.92 , respectively). For FLT and PYR, which usually show a high tendency to distribute between gas and particulate phases, the prediction accuracy was noticeably high across all sites-i.e. RMSE ranged from 0.35 to 0.59 (91 to $100 \%$ of data points were predicted within 1 order of magnitude accuracy). In order to test whether the default $\mathrm{OM}$ mass mixing ratios applied here had an impact on model predictions, the Grenoble data set was reanalyzed using the measured fraction of water-soluble organic matter in PM ( $f_{\text {WSOM: }}$ : phase $\mathrm{A}$ and $f_{\text {polymer }}=1-f_{\text {WSOM: }}$ : phase $\mathrm{B}$ ).

The results presented in Table 1 and Figure S3 show a minor change in the model performance, which can be summarized in the increase in RMSE of 0.04-0.13. In addition, the ppLFER predictions were not found sensitive to soot surface area (i.e., RMSE for $K_{\mathrm{p}}$ differed by up to $0.03 \mathrm{log}$ unit for the wide range of 3.6 to $62.70 \mathrm{~m}^{2} \mathrm{~g}^{-1}$; Table S5). Overall, these results suggest that the ppLFER model applied here is sufficient for accurately predicting the gas-particle partitioning of PAHs with various vapor pressures, because of its good prediction power and, more importantly, because it shows no substantial intersite variability related to PM compositions and sources.

The performance of the proposed multiphase ppLFER model was evaluated for substances other than PAHs (see Section S6.2), namely polychlorinated dibenzofurans (PCDFs, own data; Figure S4), nitro- and oxy-PAHs, ${ }^{56}$ and monoaromatic compounds (Figure S5). ${ }^{13}$ The model predicted the observed partitioning constants for these substance classes with a good accuracy and RMSE as low as $0.30,0.33$, and 0.52 , respectively (see Section S6.2, Figures S4 and S5). In conclusion, the model performs reasonably well for nonionic mono- and polyaromatic compounds discussed here, particularly when experimentally determined Abraham solute descriptors are used.

Figure 2 shows the median contribution of each phase to the $K_{\mathrm{P}}$ determined using multiphase ppLFER with measured $f_{\text {WSOM }}$ for the Grenoble samples $(n=114)$. We selected this site due to the availability of all supporting data needed for this analysis
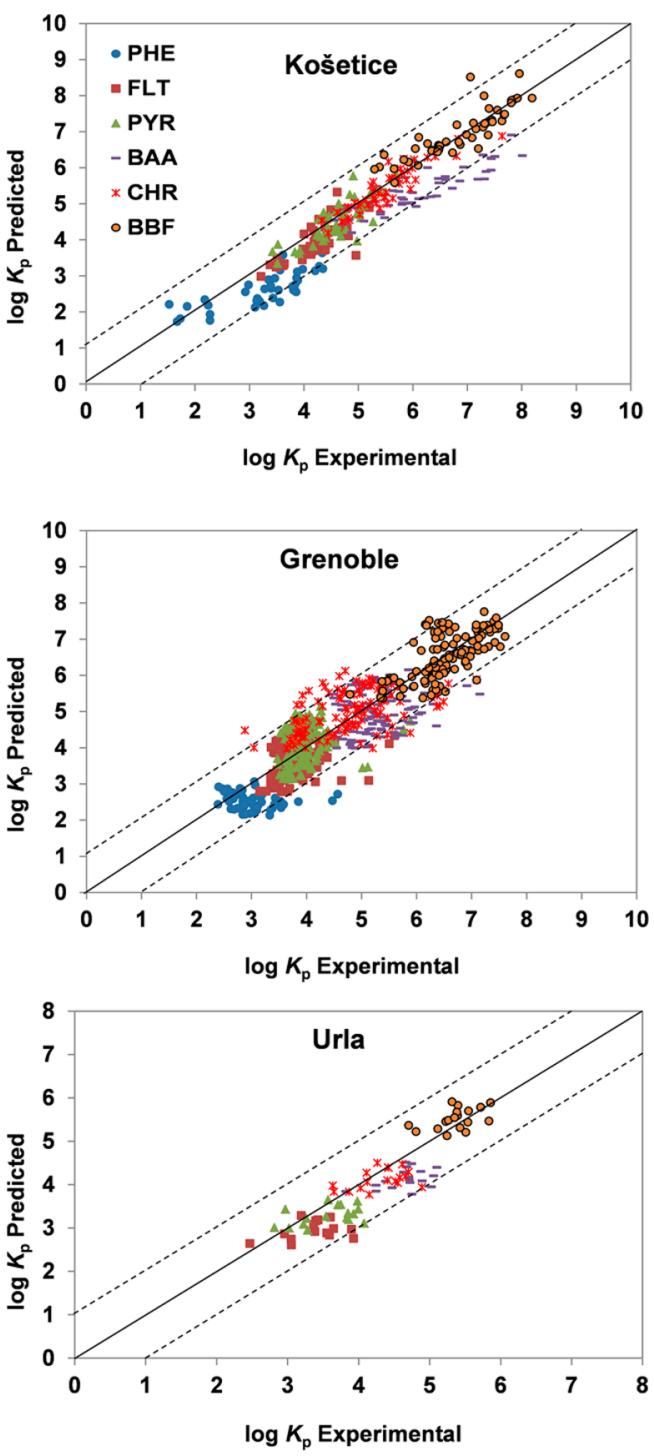

Figure 1. Predicted versus experimental $\log K_{\mathrm{p}}\left(\mathrm{m}_{\text {air }}^{3} \mathrm{~g}_{\mathrm{PM}}^{-1}\right)$, multiphase ppLFER model; $n=46,114$, and 18 for Košetice, Grenoble, and Urla, respectively.

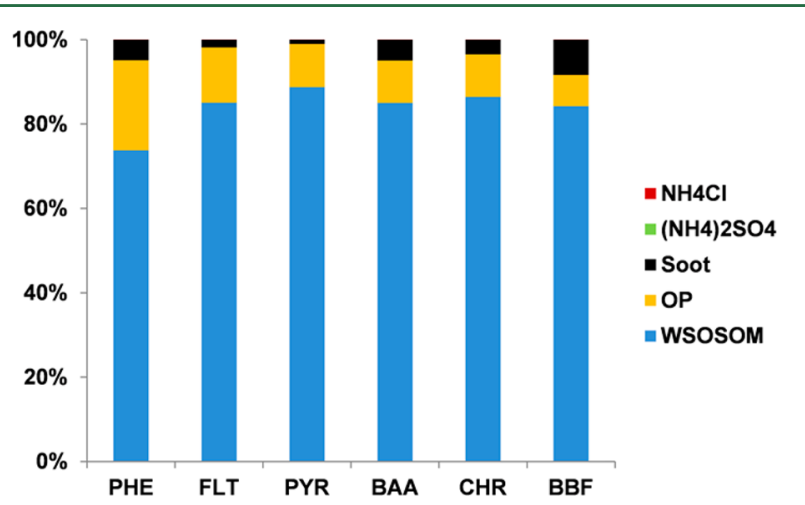

Figure 2. Median contributions of individual phases to $K_{\mathrm{P}}$ determined using multiphase ppLFER for Grenoble samples with measured subfractions. The contributions from $\left(\mathrm{NH}_{4}\right)_{2} \mathrm{SO}_{4}$ and $\mathrm{NH}_{4} \mathrm{Cl}$ are $<0.1 \%$ and are not visible in the graph.

(see Section S4). The phase contributions reflect the extent of molecular interactions between PAHs and each PM phase considered here, but to a certain extent they also reflect the 
choice of surrogates and assigned mixing ratios for each phase. As can be seen from the figure, phase 'A' contributed between 74 and $89 \%$ to the $K_{\mathrm{P}}$ across individual substances, while this ranged between 7 and $21 \%$ for Phase ' $\mathrm{B}$ ', despite allocating the $\mathrm{OM}$ mixing ratio of 0.4 to the latter. Although this could suggest a higher importance of WSOSOM for PAH gas-particle partitioning, we did not find a significant correlation between $\theta$ for semivolatile PAHs (e.g., FLT and PYR) and $f_{\text {WSOM }}$ for the Grenoble data set $(P>0.05)$. This could partly be due to the narrow range of $f_{\text {WSOM }}$ found for these samples (i.e., $0.46 \pm$ 0.08 mean \pm standard deviation) or the effect of temperature during sampling intervals (Figure S1).

Among the matrices that were considered for $\mathrm{PAH}$ adsorption, soot made the highest contribution accounting for $1-8 \%$ of the $K_{\mathrm{P}}$, with the highest value for BBF. This may be related to relatively higher $\pi$-donor ability of this compound, which would promote $\pi-\pi$ interaction with soot surface. ${ }^{41}$ Setting the soot surface area to the higher value of $62.7 \mathrm{~m}^{2} \mathrm{~g}^{-1}$ increased the share of adsorption onto soot to 3-24\%, while it decreased the shares for absorption into phases A and B to 6687 and $6-19 \%$. On the contrary, choosing the lower surface area of $3.6 \mathrm{~m}^{2} \mathrm{~g}^{-1}$ reduced the contribution of adsorption onto soot to $\leq 2 \%$. The results showed that the contributions from salts were negligible - adsorption to $\left(\mathrm{NH}_{4}\right)_{2} \mathrm{SO}_{4}$ and $\mathrm{NH}_{4} \mathrm{Cl}$ contributed to $<0.1 \%$ of the $K_{\mathrm{P}}$; however, the magnitude of adsorption was much higher for $\left(\mathrm{NH}_{4}\right)_{2} \mathrm{SO}_{4}$ (a factor of $30 \pm$ 2) than for $\mathrm{NH}_{4} \mathrm{Cl}$. Overall, the results suggest that adsorption to matrices other than soot may be neglected for modeling PAH gas-particle partitioning.

4.3. Comparison with spLFER Models. 4.3.1. JungePankow Model. Figure S6 illustrates median $c_{\mathrm{J}}$ values for the target PAHs. $\mathcal{c}_{\mathrm{J}}$ is a constant in the Junge-Pankow model and depends on analyte physicochemical properties and ambient temperature; it can be determined using measured $\theta$, PM surface concentration, $S$, and temperature-corrected $p_{\mathrm{L}}{ }^{0}$ (see Section S2 for details). Aerosol S, calculated based on PM number size distribution, was fairly similar across seasons, except in spring 2012, when a higher median value was found (Figure S7). Pankow ${ }^{27}$ suggested an estimate of $171 \mathrm{~Pa} \mathrm{~cm}$ for PAHs, but even values higher than that were suggested based on field experiments of urban aerosols in the Mediterranean. ${ }^{57}$ Nevertheless, a value of $17.2 \mathrm{~Pa} \mathrm{~cm}$ was often used for unspecified sorbent following Junge. ${ }^{26}$ In the present study, the median $c_{\mathrm{J}}$ values determined for PAHs were noticeably lower than those suggested by previous studies (Figure S6 and Table S6). Such discrepancies may not be surprising considering that the model does not account for sorbent properties or bulk phase composition and the state of atmospheric aerosol particles. Overall, different values found for individual PAHs may suggest that there is a need to use substance-specific $c_{\mathrm{J}}$ for more accurate prediction in future studies.

To be consistent with previous studies, we assumed $c_{\mathrm{J}}=17.2$ $\mathrm{Pa} \mathrm{cm}$. Figure S8 shows $\log K_{\mathrm{P}}$ values for selected PAHs predicted using the Junge-Pankow model for Košetice, plotted against experimental $\log K_{\mathrm{P}}$. Due to the lack of $S$ data, this model was not applied to the data sets from Grenoble and Urla. As can be seen from Table 1, 81 to $89 \%$ of the data points were predicted within 1 order of magnitude accuracy for PHE, FLT, PYR, and BAA with RMSE of $0.70-0.80$, while only $48 \%$ of the data was predicted with such accuracy for CHR and BBF (RMSE: 1.17 and 1.31, respectively). Despite these results, the model demonstrated an overall tendency for overestimating the $K_{\mathrm{P}}$ (Figure S8), possibly due to the overestimation of $S-$ i.e. the available surface for $\mathrm{PAH}$ adsorption was smaller than that calculated based on PM number size distribution. Another explanation could be that a high $c_{\mathrm{J}}$ value was used; the median experimental $c_{\mathrm{J}}$ for $\mathrm{CHR}$ and $\mathrm{BBF}$ was $1.7 \mathrm{~Pa} \mathrm{~cm}$, while these values were 5.2-6.9 $\mathrm{Pa} \mathrm{cm}$ for PHE, FLT, PYR, and BAA (Table S6).

4.3.2. Finizio and Dachs-Eisenreich Models. Figure S9 shows $\log K_{\mathrm{P}}$ for the PAHs predicted using Finizio $\left(K_{\mathrm{oa}}\right)$ and Dachs-Eisenreich (dual absorption-adsorption) models against the experimental values. As can be seen from the figure and Table 1, the Finizio model underestimated the experimental $K_{\mathrm{P}}$ for PHE, FLT, PYR, and BAA in most cases by more than 1 order of magnitude (RMSE of $\log K_{\mathrm{P}}$ : $0.95-1.40$ ) but not for CHR (0.62-0.71). Moreover, predictions for BBF were better at Urla (RMSE: 0.64) than at Košetice and Grenoble (RMSE: 0.85 and 0.96). Previous studies showed that the model of Finizio could underestimate the PAH partitioning constants by more than 1 order of magnitude. ${ }^{9,16,17}$ In the present study, predictions made with the Dachs-Eisenreich model (i.e., adding the contribution of adsorption onto soot) increased the magnitude of $K_{\mathrm{P}}$ but not substantially (Table 1 and Figure S9). This may not be surprising if we consider that the partitioning process was mainly dominated by absorption into organic matter (Figure S10). This was more pronounced for data from Košetice and Urla and for PAHs with relatively low vapor pressure, namely BAA, CHR, and BBF. The DachsEisenreich model was found more sensitive to the soot surface area than the ppLFER model - RMSE values were reduced by up to $0.17 \log$ unit with maximum surface area input $\left(62.7 \mathrm{~m}^{2}\right.$ $\mathrm{g}^{-1}$; Table S5) and increased by up to $0.10 \log$ unit with minimum surface area $\left(3.6 \mathrm{~m}^{2} \mathrm{~g}^{-1}\right.$; Table S5).

Underprediction of the observed $\mathrm{PAH}$ partitioning constants noted in the previous studies have led some authors to suggest that the presence of nonexchangeable PAHs buried within PM may cause nonequilibrium conditions in the atmosphere, and, consequently, the PAH mass determined through conventional solvent extraction techniques may have been overestimated. ${ }^{13,16}$ However, analyte nonexchangeability in the atmosphere could only be expected under low relative humidity and temperature, such as in the free troposphere, due to kinetic constraints caused by slow diffusion in glassy or semisolid bulk organic matter. ${ }^{58-60}$ Such conditions may have hardly affected the aerosols studied here, which were transported mostly close to sources and within the boundary layer.

\section{RECOMMENDATIONS FOR FUTURE MODEL APPLICATION}

The ppLFER model presented here showed promising results in predicting $\mathrm{PAH}$ gas-particle partitioning constants with RMSE for semivolatile FLT and PYR ranging from 0.35-0.59 log unit. Furthermore, it was tested on other relevant substance classes (i.e., PCDFs, nitro- and oxy-PAHs, ${ }^{56}$ and substituted monoaromatics) with reasonably good predictions and RMSE as low as $0.30 \log$ unit. Although limited by solute descriptor availability, the ppLFER model should be considered a better choice for describing sorption processes; however, only with good representative surrogates for various OM classes, its full potential can be realized. A better knowledge of the OM composition, in particular nonelutable and unresolved mass fractions, is needed for more realistic allocation of surrogate substances to $\mathrm{OM}$ categories. The identification of the OM phase-state ${ }^{54}$ is an additional parameter to be included in future parametrizations of gas-particle partitioning. 


\section{ASSOCIATED CONTENT}

\section{S Supporting Information}

The Supporting Information is available free of charge on the ACS Publications website at DOI: 10.1021/acs.est.6b02158.

Model calculation methods, ppLFER substance and system parameters, aerosol composition data sets, and additional tables and graphs related to model predictions (PDF)

\section{AUTHOR INFORMATION}

\section{Corresponding Authors}

*Phone: +496131 305 7602. E-mail: p.shahpoury@mpic.de (P.S.).

*Phone: +496131 305 7601. E-mail: g.lammel@mpic.de (G.L.). Corresponding author address: Multiphase Chemistry Department, Max Planck Institute for Chemistry, HahnMeitner-Weg-1, 55128 Mainz, Germany.

Notes

The authors declare no competing financial interest.

\section{ACKNOWLEDGMENTS}

We thank Michael H. Abraham (University College London) and Satoshi Endo (Osaka City University) for discussions about ppLFER. We also thank Petra Přibylová (Masaryk University), Nadine Guillaumet, Noémie Nuttens (Air RhôneAlpes, St. Martin d'Hères, France), and Gürdal Tuncel (Middle East Technical University, Ankara) for analytical support and Adela Holubová Šmejkalová, Milan Váňa (Czech Hydrometeorological Institute), Nathalie Bocquet, and Robin Aujay (Air Rhône-Alpes) for sampling and providing meteorological and air quality data. This research was partly supported by the Granting Agency of the Czech Republic (GACR project no. P503/11/1230) and the Izmir Institute of Technology Scientific Research Foundation (2013-IYTE-14) and was cofunded by the Czech Ministry of Education, Youth and Sports (LO1214 and LM2015051) and the French Ministry of Environment, Energy and Sea (MEEM). INERIS work was done as part of the LCSQA activities (French Central Laboratory for Air Quality Monitoring).

\section{REFERENCES}

(1) Franklin, J.; Atkinson, R.; Howard, P. H.; Orlando, J. J.; Seigneur, C.; Wallington, T. J.; Zetzsch, C. Quantitative determination of persistence in air. In Evaluation of Persistence and Long-Range Transport of Chemicals in the Environment; Klečka, G., et al., Eds.; SETAC Press: Pensacola, USA, 2000; pp 7-62.

(2) Bidleman, T. F. Atmospheric processes. Environ. Sci. Technol. 1988, 22 (4), 361-367.

(3) Finlayson-Pitts, B. J.; Pitts, J. N. Chemistry of the Upper and Lower Atmosphere: Theory, Experiments, Application; Academic Press: San Diego, USA, 2000.

(4) Lammel, G.; Sehili, A. M.; Bond, T. C.; Feichter, J.; Grassl, H. Gas/particle partitioning and global distribution of polycyclic aromatic hydrocarbons - a modelling approach. Chemosphere 2009, 76 (1), 98-106.

(5) IARC. Monographs on the evaluation of carcinogenic risks to humans, some non-heterocyclic polycyclic aromatic hydrocarbons and some related exposures; International Agency for Research on Cancer, World Health Organization: Lyon, France, 2010. http://monographs.iarc.fr/ ENG/Monographs/vol92/mono92.pdf (accessed Oct 18, 2016).

(6) EU-WGPAH. Ambient air pollution by polycyclic aromatic hydrocarbons; European Union Working Group on Polycylic Aromatic Hydrocarbons: Luxembourg, 2001. http://ec.europa.eu/environment/ air/pdf/pp_pah.pdf (accessed Oct 18, 2016).
(7) WHO-ECEH. Health risks of persistent organic pollutants from long-range transboundary air pollution; European Centre for Environment and Health, World Health Organization: Bonn, Germany, 2003. http://www.euro.who.int/_data/assets/pdf_file/0009/78660/ e78963.pdf (accessed Oct 18, 2016).

(8) Shahpoury, P.; Hageman, K. J.; Matthaei, C. D.; Alumbaugh, R. E.; Cook, M. E. Increased concentrations of polycyclic aromatic hydrocarbons in alpine streams during annual snowmelt: investigating effects of sampling method, site characteristics, and meteorology. Environ. Sci. Technol. 2014, 48 (19), 11294-11301.

(9) Lohmann, R.; Lammel, G. Adsorptive and absorptive contributions to the gas-particle partitioning of polycyclic aromatic hydrocarbons: state of knowledge and recommended parametrization for modeling. Environ. Sci. Technol. 2004, 38 (14), 3793-3803.

(10) Shahpoury, P.; Lammel, G.; Holubová Šmejkalová, A.; Klánová, J.; Přibylová, P.; Váňa, M. Polycyclic aromatic hydrocarbons, polychlorinated biphenyls, and chlorinated pesticides in background air in central Europe - investigating parameters affecting wet scavenging of polycyclic aromatic hydrocarbons. Atmos. Chem. Phys. 2015, 15 (4), 1795-1805.

(11) Škrdlíková, L.; Landlová, L.; Klánová, J.; Lammel, G. Wet deposition and scavenging efficiency of gaseous and particulate phase polycyclic aromatic compounds at a central European suburban site. Atmos. Environ. 2011, 45 (25), 4305-4312.

(12) Goss, K.-U.; Schwarzenbach, R. P. Linear free energy relationships used to evaluate equilibrium partitioning of organic compounds. Environ. Sci. Technol. 2001, 35 (1), 1-9.

(13) Arp, H. P. H.; Schwarzenbach, R. P.; Goss, K.-U. Ambient gas/ particle partitioning. 2: the influence of particle source and temperature on sorption to dry terrestrial aerosols. Environ. Sci. Technol. 2008, 42 (16), 5951-5957.

(14) Landlová, L.; Cuupr, P.; Franců, J.; Klánová, J.; Lammel, G. Composition and effects of inhalable size fractions of atmospheric aerosols in the polluted atmosphere: Part I. PAHs, PCBs and OCPs and the matrix chemical composition. Environ. Sci. Pollut. Res. 2014, 21 (9), 6188-6204.

(15) Götz, C. W.; Scheringer, M.; MacLeod, M.; Roth, C. M.; Hungerbühler, K. Alternative approaches for modeling gas-particle partitioning of semivolatile organic chemicals: model development and comparison. Environ. Sci. Technol. 2007, 41 (4), 1272-1278.

(16) Harner, T.; Bidleman, T. F. Octanol-air partition coefficient for describing particle/gas partitioning of aromatic compounds in urban air. Environ. Sci. Technol. 1998, 32 (10), 1494-1502.

(17) Dachs, J.; Eisenreich, S. J. Adsorption onto aerosol soot carbon dominates gas-particle partitioning of polycyclic aromatic hydrocarbons. Environ. Sci. Technol. 2000, 34 (17), 3690-3697.

(18) He, J.; Balasubramanian, R. A study of gas/particle partitioning of SVOCs in the tropical atmosphere of Southeast Asia. Atmos. Environ. 2009, 43 (29), 4375-4383.

(19) Wang, W.; Simonich, S. L. M.; Wang, W.; Giri, B.; Zhao, J.; Xue, M.; Cao, J.; Lu, X.; Tao, S. Atmospheric polycyclic aromatic hydrocarbon concentrations and gas/particle partitioning at background, rural village and urban sites in the North China Plain. Atmos. Res. 2011, 99 (2), 197-206.

(20) Gaga, E. O.; Ari, A. Gas-particle partitioning of polycyclic aromatic hydrocarbons (PAHs) in an urban traffic site in Eskisehir, Turkey. Atmos. Res. 2011, 99 (2), 207-216.

(21) Sangiorgi, G.; Ferrero, L.; Perrone, M. G.; Papa, E.; Bolzacchini, E. Semivolatile $\mathrm{PAH}$ and $\mathrm{n}$-alkane gas/particle partitioning using the dual model: up-to-date coefficients and comparison with experimental data. Environ. Sci. Pollut. Res. 2014, 21 (17), 10163-10173.

(22) Roth, C. M.; Goss, K.-U.; Schwarzenbach, R. P. Sorption of a diverse set of organic vapors to urban aerosols. Environ. Sci. Technol. 2005, 39 (17), 6638-6643.

(23) Lammel, G.; Audy, O.; Besis, A.; Efstathiou, C.; Eleftheriadis, K.; Kohoutek, J.; Kukučka, P.; Mulder, M. D.; Přibylová, P.; Prokeš, R.; Rusina, T. P.; Samara, C.; Sofuoglu, A.; Sofuoglu, S. C.; Taşdemir, Y.; Vassilatou, V.; Voutsa, D.; Vrana, B. Air and seawater pollution and air-sea gas exchange of persistent toxic substances in the Aegean Sea: 
spatial trends of PAHs, PCBs, OCPs and PBDEs. Environ. Sci. Pollut. Res. 2015, 22 (15), 11301-11313.

(24) Kamprad, I.; Goss, K.-U. Systematic investigation of the sorption properties of polyurethane foams for organic vapors. Anal. Chem. 2007, 79 (11), 4222-4227.

(25) Yamasaki, H.; Kuwata, K.; Miyamoto, H. Effects of ambient temperature on aspects of airborne polycyclic aromatic hydrocarbons. Environ. Sci. Technol. 1982, 16 (4), 189-194.

(26) Junge, C. E. Fate of Pollutants in the Air and Water Environments; John Wiley and Sons, Inc.: New York, 1977.

(27) Pankow, J. F. Review and comparative analysis of the theories on partitioning between the gas and aerosol particulate phases in the atmosphere. Atmos. Environ. 1987, 21 (11), 2275-2283.

(28) Finizio, A.; Mackay, D.; Bidleman, T.; Harner, T. Octanol-air partition coefficient as a predictor of partitioning of semi-volatile organic chemicals to aerosols. Atmos. Environ. 1997, 31 (15), 22892296.

(29) Abraham, M. H. Scales of solute hydrogen-bonding: their construction and application to physicochemical and biochemical processes. Chem. Soc. Rev. 1993, 22 (2), 73-83.

(30) Goss, K.-U. Predicting the equilibrium partitioning of organic compounds using just one linear solvation energy relationship (LSER). Fluid Phase Equilib. 2005, 233 (1), 19-22.

(31) Endo, S.; Goss, K. U. Applications of polyparameter linear free energy relationships in environmental chemistry. Environ. Sci. Technol. 2014, 48 (21), 12477-12491.

(32) Krivácsy, Z.; Kiss, G.; Ceburnis, D.; Jennings, G.; Maenhaut, W.; Salma, I.; Shooter, D. Study of water-soluble atmospheric humic matter in urban and marine environments. Atmos. Res. 2008, 87 (1), $1-12$.

(33) Rogge, W. F.; Mazurek, M. A.; Hildemann, L. M.; Cass, G. R.; Simoneit, B. R. T. Quantification of urban organic aerosols at a molecular level: identification, abundance and seasonal variation. Atmos. Environ., Part A 1993, 27 (8), 1309-1330.

(34) Kalberer, M.; Paulsen, D.; Sax, M.; Steinbacher, M.; Dommen, J.; Prevot, A. S. H.; Fisseha, R.; Weingartner, E.; Frankevich, V.; Zenobi, R.; Baltensperger, U. Identification of polymers as major components of atmospheric organic aerosols. Science 2004, 303 (5664), 1659-1662.

(35) Puxbaum, H.; Tenze-Kunit, M. Size distribution and seasonal variation of atmospheric cellulose. Atmos. Environ. 2003, 37 (26), 3693-3699.

(36) Després, V. R.; Alex Huffman, J.; Burrows, S. M.; Hoose, C.; Safatov, A. S.; Buryak, G.; Fröhlich-Nowoisky, J.; Elbert, W.; Andreae, M. O.; Pöschl, U.; Jaenicke, R. Primary biological aerosol particles in the atmosphere: a review. Tellus, Ser. B 2012, 64 (15598), 1-58.

(37) Erdakos, G. B.; Pankow, J. F. Gas/particle partitioning of neutral and ionizing compounds to single- and multi-phase aerosol particles. 2 . Phase separation in liquid particulate matter containing both polar and low-polarity organic compounds. Atmos. Environ. 2004, 38 (7), 10051013.

(38) Turpin, B. J.; Lim, H. J. Species contributions to PM2.5 mass concentrations: Revisiting common assumptions for estimating organic mass. Aerosol Sci. Technol. 2001, 35 (1), 602-610.

(39) Paula, A. S.; Matos, J. T. V.; Duarte, R. M. B. O.; Duarte, A. C. Two chemically distinct light-absorbing pools of urban organic aerosols: a comprehensive multidimensional analysis of trends. Chemosphere 2016, 145, 215-223.

(40) Zhu, D.; Hyun, S.; Pignatello, J. J.; Lee, L. S. Evidence for $\pi-\pi$ electron donor-acceptor interactions between $\pi$-donor aromatic compounds and $\pi$-acceptor sites in soil organic matter through $\mathrm{pH}$ effects on sorption. Environ. Sci. Technol. 2004, 38 (16), 4361-4368. (41) Zhu, D.; Pignatello, J. J. Characterization of aromatic compound sorptive interactions with black carbon (charcoal) assisted by graphite as a model. Environ. Sci. Technol. 2005, 39 (7), 2033-2041.

(42) Pietrogrande, M. C.; Bacco, D.; Chiereghin, S. GC/MS analysis of water-soluble organics in atmospheric aerosol: optimization of a solvent extraction procedure for simultaneous analysis of carboxylic acids and sugars. Anal. Bioanal. Chem. 2013, 405 (2), 1095-1104.
(43) EPI-Suite. Estimation Programs Interface Suite for Microsoft $\AA$ Windows, v 4.11; United States Environmental Protection Agency: 2012.

(44) ACD/Labs. Absolv; Advanced Chemistry Development, Inc.: Toronto, Canada, 2015.

(45) Schwarzenbach, R. P.; Gschwend, P. M.; Imboden, D. M. Sorption I: general introduction and sorption processes involving organic matter. In Environmental Organic Chemistry; John Wiley \& Sons, Inc.: 2005; pp 275-330.

(46) Kiss, G.; Tombácz, E.; Varga, B.; Alsberg, T.; Persson, L. Estimation of the average molecular weight of humic-like substances isolated from fine atmospheric aerosol. Atmos. Environ. 2003, 37 (27), $3783-3794$.

(47) Saxena, P.; Hildemann, L. M. Water-soluble organics in atmospheric particles: a critical review of the literature and application of thermodynamics to identify candidate compounds. J. Atmos. Chem. 1996, 24 (1), 57-109.

(48) Holmgren, T.; Persson, L.; Andersson, P. L.; Haglund, P. A generic emission model to predict release of organic substances from materials in consumer goods. Sci. Total Environ. 2012, 437, 306-314.

(49) Roth, C. M.; Goss, K.-U.; Schwarzenbach, R. P. Sorption of a diverse set of organic vapors to diesel soot and road tunnel aerosols. Environ. Sci. Technol. 2005, 39 (17), 6632-6637.

(50) Goss, K.-U.; Buschmann, J.; Schwarzenbach, R. P. Determination of the surface sorption properties of talc, different salts, and clay minerals at various relative humidities using adsorption data of a diverse set of organic vapors. Environ. Toxicol. Chem. 2003, 22 (11), 2667-2672.

(51) Mintz, C.; Burton, K.; Acree, W. E., Jr.; Abraham, M. H. Enthalpy of solvation correlations for gaseous solutes dissolved in dimethyl sulfoxide and propylene carbonate based on the Abraham model. Thermochim. Acta 2007, 459 (1-2), 17-25.

(52) Goss, K.-U. The air/surface adsorption equilibrium of organic compounds under ambient conditions. Crit. Rev. Environ. Sci. Technol. 2004, 34 (4), 339-389.

(53) Jonker, M. T. O.; Koelmans, A. A. Sorption of polycyclic aromatic hydrocarbons and polychlorinated biphenyls to soot and soot-like materials in the aqueous environment: mechanistic considerations. Environ. Sci. Technol. 2002, 36 (17), 3725-3734.

(54) Koop, T.; Bookhold, J.; Shiraiwa, M.; Poschl, U. Glass transition and phase state of organic compounds: dependency on molecular properties and implications for secondary organic aerosols in the atmosphere. Phys. Chem. Chem. Phys. 2011, 13 (43), 19238-19255.

(55) You, Y.; Smith, M. L.; Song, M.; Martin, S. T.; Bertram, A. K. Liquid-liquid phase separation in atmospherically relevant particles consisting of organic species and inorganic salts. Int. Rev. Phys. Chem. 2014, 33 (1), 43-77.

(56) Tomaz, S.; Shahpoury, P.; Jaffrezo, J.-L.; Lammel, G.; Perraudin, E.; Villenave, E.; Albinet, A. One-year study of polycyclic aromatic compounds at an urban site in Grenoble (France): seasonal variations, gas/particle partitioning and cancer risk estimation. Sci. Total Environ. 2016, 565, 1071-1083.

(57) Lammel, G.; Klánová, J.; Ilić, P.; Kohoutek, J.; Gasić, B.; Kovacić, I.; Škrdlíková, L. Polycyclic aromatic hydrocarbons in air on small spatial and temporal scales - II. mass size distributions and gasparticle partitioning. Atmos. Environ. 2010, 44 (38), 5022-5027.

(58) Zhou, S.; Shiraiwa, M.; McWhinney, R. D.; Pöschl, U.; Abbatt, J. P. D. Kinetic limitations in gas-particle reactions arising from slow diffusion in secondary organic aerosol. Faraday Discuss. 2013, 165 (0), 391-406.

(59) Shiraiwa, M.; Ammann, M.; Koop, T.; Pöschl, U. Gas uptake and chemical aging of semisolid organic aerosol particles. Proc. Natl. Acad. Sci. U. S. A. 2011, 108 (27), 11003-11008.

(60) Zelenyuk, A.; Imre, D.; Beránek, J.; Abramson, E.; Wilson, J.; Shrivastava, M. Synergy between secondary organic aerosols and longrange transport of polycyclic aromatic hydrocarbons. Environ. Sci. Technol. 2012, 46 (22), 12459-12466. 